\title{
Document Management System Mobility - Main Trend in Future Document Management
}

\author{
T. Leikums, Member, IACSIT
}

\begin{abstract}
During the last few years the circulation of electronic documents has become one of the main elements of information technology (IT) development in the public sector. Governmental institutions implement electronic document management systems, reciprocally exchange digitally signed documents, develop internal and external normative acts and distribute them electronically. However, IT development is as always rapid and document management systems, acquired or created some years ago, not always provide optimal functionality nowadays. This is caused by the rapid spread of mobile technologies. Document management systems which are originally created for usage in stationary and portable computers are not always adaptable for convenient usage in tablet PCs and mobile phones. Thus it is clear that in the near future the main trend of electronic document management will be the adaptation for mobile devices. The main aim of this article is to determine what is the relationship between document management systems and mobile devices and if the main future trend of electronic document management will be adaptation for mobile devices. The results show that mobile devices, though inevitably connected to future development of DMS, can also also cause security breaches.
\end{abstract}

Index Terms-Electronic document management, document management systems, mobility.

\section{INTRODUCTION}

Electronic document management is on the verge of a new challenge. Even if many governmental institutions have not yet accomplished the transition to a completely electronic document circulation, they already have to engage in a search for future solutions. „In recent years, there has been an explosion in mobile computing and telecommunications technologies. A lot of work is done outside the office in different and unpredictable locations" [1]. The mobility of information systems (incl. document management systems) is not only an extra feature - it has become a necessity, required both by general managers and common users. Ministers, state secretaries, directors and other managers spend most of their time out of office - in meetings, planning sessions, visitations and business missions. However, the document flow in governmental institutions is hugely dependent on them. Without the resolution of managers one cannot start the original procession of incoming documents, without the signature of the manager the documents cannot be sent forth. This increases the significance of document management systems (DMS), yet this system has to be available from the internet and usable in mobile devices.

Manuscript received February 10, 2013; revised April 17, 2013.

T. Leikums is with the Latvia University of Agriculture, Jelgava, Latvia (e-mail: toms_leikums@programmer.net).
This article analyses electronic document management in governmental institutions: document management systems and their history, users and usage habits, development trends and document management process from mobile devices. Special attention has been paid to requirements for document management systems to make them convenient and functional from tablets PCs, handheld PCs and mobile phones.

\section{DMS DEVELOPMENT HISTORY}

Up until the middle of the first decade of the new millennium electronic document management systems were mainly local - with client-side software which would be installed on customers' PCs und available only from the local area network of the company. Yet even then the developers were trying to find different ways to ensure DMS mobility and options to use it outside the working place. In 1995 a company Saros Corp. issued the newest version of their document management system Document Manager 1.50 which among other options also enabled remote working with the documents of the company [2]. It was obviously not a mobile document management system in a contemporary sense as it did not enable remote access to the document library. The relative mobility was enabled with the help of the check-in, check-out mechanism that became widely used in the industry. When the computer was connected to the company's local area network, the user could save the documents from the document management system on server and later process them anywhere. Then, when the computer was again connected to the company's network, automatic synchronisation took place and the newest version of the document was uploaded onto the server.

As the second pioneer of mobile document management systems we can mention the company PC DOCS with their DMS Docs Open [3]. In 1996 it was supplemented by a new module Docs Unplugged enabling working with the system without network connection. However, in order to make system functions complete, the work station of the client had to have an SQL server software. In order to avoid installing it on every computer, Docs Unplugged module enabled configuring and using one computer as a proxy server with a data base and it was used for connection by other work stations.

First popular DMS which were completely considered as mobile were Matrix Logic and Hummingbird products in 2001. Through Matrix Logic's wireless DMS Suite (WirelessDMS) users can access documents stored in a Hummingbird Document Management solution from anywhere via mobile phones, personal digital assistants 
(PDAs) and handheld computers. The system enabled users to remotely access the data base of the organization, perform search and even send the documents per e-mail or fax, using the mobile device only (phones, pagers, palm devices and pocket PCs).

During the last five years the developers' approach has hugely changed as the majority of DMS are being created in a way that enables to use them with the internet browser only. 'Web based document management systems are becoming very popular. The cost per user is typically more than if you purchased the product for use within your firm, but you save on the hardware and internal support costs. The vendor provides the back-end hardware and software for the management of your documents. The nice part about web-based document management systems is that the information is accessible from any computer with an Internet connection. The bad part about web-based document management systems is that the vendor is holding your data and you are subject to the reliability of the Internet connection. Inevitably, the vendor is holding your very sensitive client data. If you elect to use one of the online document management systems, be aware of the security precautions for client data that is being held by a third party' [4]. Likely the main part of document management systems will further be developed for usage in web environment. Even though their performance is lower than in systems based on locally installed client-side software (noticed by the users too, as observed by the author of the article), their usage and administration convenience make up for it. Just a few years ago documents management system administrators had to create centralized installation and software distribution packages or manually install DMS customer software on every PC of the company; now one has only to make sure that the PCs have the supported internet browser installed and send the link for accessing the document management system. Future development prospects of DMS are inspected in chapter 6 of this article - Further development of DMS.

\section{DMS USERS AND THEIR REQUIREMENTS}

In the public sector users of document management systems are mainly all the workers. The records management receive the document, scan it or place it into the system, register and pass on to general manager in order to create the resolution. The manager carries a resolution of the document and passes it on to the department managers who in their turn create tasks inside their respective departments, until the document in the hierarchical network reaches the end executor. When creating outgoing documents, the whole chain works in the opposite direction - from the creator of the document it goes through phases of reconciliation, visa and signatures to records management who send the document or deliver it to the addressee. The mobility of DMS can become topical in any of these stages. Actually the only ones who really have to work stationery are the records managers, as they have to be in the office, receive correspondence, when necessary, scan the files etc. Depending on the situation all the other mentioned users can choose to use the system outside their workplace. This is particularly important for general managers and department managers whose working duties among others consist of different meetings out of office, planning sessions and other tasks that are to be done not in front of one's computer. DMS has to be usable everywhere where there is an internet connection - in hotels, trains, cars etc. Mobile phones turned into significant work tools already several years ago, so emphasize IT specialists [5]. The majority of general managers in public institutions use some up-to-date mobile device - tablet PC, advanced mobile phone, Personal Digital Assistant (PDA). Of course, laptops are also used often, but this product group is not the study goal of this article as a DMS which is working fine on a monitor of a stationery PC, will also work fine on a laptop.

Many users emphasize their desire to work with documents also in places where there is no internet connection and this is a new challenge for DMS developers. 'According to a mobile worker, airplane is the best working environment, because there is plenty of food and peace, and no telephone. According to another mobile worker, sitting in a train is useful time because you are able to write a few emails to be sent as soon as you are able to connect the Internet' [6]. In order to ensure the performance of the document management system, the only acceptable solution now is a client-side software installation in the mobile device and the usage of the aforementioned check-in, check-out system. However, the greatest part of popular DMS developers avoid using this technological model, being content with options provided by internet and assuming that system users will not wish to work from places where world wide web is not available at all.

DMS developers understand that the vast majority of users who will use DMS from mobile devices and out of the office will most likely be managers. Therefore the mobile functions of DMS pay significantly more attention exactly to managing functions (resolution and task creation, controlling, document search) and not to functions necessary for the end user - document creation, input of nomenclature file and metadata and the like. It is certainly clear that, disregarding the convenience of the mobile DMS client, it will never be possible to completely create a corresponding document of several pages because of the size restrictions. However, it is also not a primary necessity as the requirements of mobile users of DMS are completely different. 'For a mobile worker, the most important features of mobile document management are easy access, timely access, user interface, ubiquity, and compliance with security policies. These features are also practical differences between document management using conventional ICT and mobile ICT. Current solutions in document management do not necessarily meet these requirements' [1].

However, many specialists of electronic document management also analyse the possibilities of creating document on mobile devices. Dean Tang inspects mobile data capture possibilities [7], emphasizing that it only seems complicated but actually taking photos, inserting the files into DMS and continuingly starting a business process is a trivial action. 'As the document management industry dives deeper into this age of gizmos and gadgets, it is important for mobile data capture and the cloud to be viewed as natural extensions to the information processing infrastructure' [7]. Dean Tang particularly emphasizes the performance factor of 
mobile devices, the quality of in-built cameras and processors being able to retrieve texts from pictures and recognize particular fields relevant for creating of metadata. Among other functions important for users we can mention sharing tools so that users can email and print files from the application, collaboration capabilities so that mobile users can offer feedback and edits in real time.

\section{SySTEM AND DATA SECURITY}

Security is one the most important considerations when creating any information system. However, for a system that will be used from mobile devices security issues has to be considered in an even more scrutinizing way. Data security in mobile devices and particularly in cloud computing information systems has been studied by several authors: S. Ristov, M. Gusev, M. Kostoska [8], K. W. Nafi, T. S. Kar, S. A. Hoque, M. M. A. Hashem [9]. Studies also offer security platform models for cloud computing information system [10]. When examining security issues of mobile devices, particular emphasis has to be put on the most popular of them - iPhone. V. R. Pandya and M. Stamp offer the iPhone Security Analysis [11].

State administration traditionally uses the mechanism of grouping the documents. Depending on the contents of the document and other criteria, its status can be publicly available, only for official use, restricted access or even state secret. When implementing an electronic document management system one has to carefully consider which of the aforementioned document groups should be stored in the system. Often DMS is used for standard document circulation only and other document types are used in specially certified information systems. However, even when official use only and restricted access documents are not stored in the system, the management of the institutions and systems administrators have to consider different security related questions:

1) Will it be possible to save data from DMS into mobile devices?

2) If the data will be available for saving, will it be encrypted?

3) What authentication principles will be used in the DMS when connected by a mobile client? One has to take into account that the vast majority of current document management systems are able to use Windows authentication LDAP mechanism, which is based on Active Directory.

If document management system is not available on the internet and can only be accessible from the company's local area network, it can still be used on mobile devices; however, a connection with the organization network has to be set up in advance. If choosing this solution, the security specialists and DMS administrators have to analyse what are the security implications of connecting mobile devices to the corporate network and should personal devices be allowed to connect via virtual private network (VPN) - where they have unfettered access to the entire corporate network?

Very often nowadays many people in the public sector as well want to work using their own personal mobile devices. If the workplace does not provide their workers with iPads and are not planning to do it, people sometimes buy them themselves and often wish to access company's document management system from the new device. This significantly increases the security risks for the system administrators cannot control the personal devices owned by employees. These devices can contain both viruses and fragments of executable source codes, rootkits or other threats for company's network and computer systems. Of course, in such cases it is safer to use DMS which are usable in web environment - from internet browser, thus not letting the potentially dangerous devices to connect to the local area network of the organization. This makes the inbuilt security features of the DMS itself very important as even a single document containing a virus, if uploaded to the common document repository, can threaten not only with the leakage of information, but also with the destruction of the whole system.

\section{Mobile Platforms AND SOlutions}

Certainly the most popular mobile device is nowadays iPhone. This is apprehended by document management system developers as well. For example, in the middle of 2011 the document and business process management company Laserfiche released Laserfiche Mobile, an iPhone app that allows the user to capture an image with the phone's built-in camera and then put it into the stream of a managed workflow. This application not only allows creating of new documents but also searching and processing of already existing documents, as well as taking part into different workflows - visa, reconcile documents and create tasks. Other companies are not falling behind Laserfiche, for example, Microsoft offers different options on how to use the SharePoint system from different mobile devices, DocPath promotes its new technology Ipanema, which allows any user to apply mobility options to all document software and to provide the answers to the needs that are generated in business every day. The situation is slightly different in the market of Android operational systems. Even though the total number of active Android devices is much higher than Apple products, many major DMS developers avoid the Android platform. As far as until 2011 Android users even did not have the option to access Microsoft SharePoint; the situation changed only after third party developers Infragistics and Azurati developed the respective solutions of Shareplus and SharePoint2Go. Although one of the major electronic document management players OpenText offers enterprise content management for all the most popular platforms: BlackBerry, iOS and Android. The advantages of Adroid versus iPhone has been also emphasized by K. Sharma [12].

One can assume that in the future the biggest DMS developers will continue to follow the newest trends and update their document management system software and applications to make them available from the most popular mobile operational systems.

\section{FURTHER DEVELOPMENT OF DMS}

Analyst Katey Wood of the Enterprise Strategy Group 
identifies five document management trends [13]. The author of the article would like to emphasize two of them as the most important: cloud-computing and mobility. Cloud-computing is often related to passing all the data of an organization to a third party. The study „Electronic Document Management Outsourcing and Cloud-Computing Possibilities for Public Sector" [14] pays close attention to four different options available for document management: full outsourcing of all document management processes, outsourcing of all IT services related to document management, using an system-as-a-service document management system, using a local document management system. Only the latter of the aforementioned options includes storing and controlling the documents internally. Katey Wood also emphasizes that it has to be a decision of the company - whether to trust the data to a third party: 'IT managers must decide if it works for their organization to manage storage in the cloud and, if so, what levels of privacy and security the third-party provider needs to deliver. Do agencies want all their contracts, transcripts and financial records in the cloud? Or do they want to store only unclassified e-mail records?' [13]. Cloud-computing offer many advantages: avoiding technical decisions, specialist help in the optimization of document circulation process, short implementation period, more comfortable document access for end users, following the advices of good practices [14].

Cloud-computing is closely related to mobility of document management systems. DMS working in-cloud can almost always be accessible remotely, using internet. However, in no way it guarantees that the system would be usable from mobile devices too. This problems is underlined by Katey Wood: 'As workers become more mobile, IT managers have to decide to what extent an organization's document management system will accommodate the many mobile devices coming into the workplace. For example, will staff be able to access documents on their tablets and smartphones?' [13].

Examining further trends of DMS development, Dean Tang points out that the future belongs to cloud-based DMS, being able to ensure qualitative capturing mechanism in mobile devices. The specialist emphasizes that 'whichever way enterprise organizations eventually move, the document management ecosystem will need to change in parallel to provide the document management services required in a mobile environment' [7]. Same as Dean Tang, Andre W. Klein also claims that exactly the document capturing and creation is the most important issue of further development of mobile DMS: 'As time continues, the mixture of document management software and mobile technology will open several choices. You'll be able to create documents utilizing a mobile phone, utilizing a camera or OCR software (to send a scanned document in editable format or digitalize articles or documents written on paper and send them to through our central document manager to the rest from the employees, working on a specific subject within the organization)' [15].

However, not all the specialists agree that the development trend towards mobility should be regarded only positively. Sari Makinen doubts if the new trend will increase the overall quality of organization information: 'The challenges of mobile devices and mobile working environment to document management and especially records management are varied and still largely unexplored. It is clear that the explosion of mobile computing will not improve or ease the augmentation of organizational memory, which is strictly connected to individuals' [1]. One has to take into account that documents created with mobile devices can be of much lower quality. The personal experience of the author of the article with implementation of different DMS gives evidence that the desire of workers to adapt the system for using it from mobile devices can cause problems for the general interface of the system and delay other important tasks of document management system development and implementation. Mobility of DMS should never become and end in itself.

The information system developers have to understand system mobility is not only a technological issue anymore. It is somehow become the way of thinking of the users. During the last few years people have grown used that electronic mail and different information systems are not connected to one's workplace anymore where the stationery computer is located. Among others, the mobility of information systems as a basic strategic element for organizational development has been emphasized by Sanjeev Narayan Bal: 'Mobile enterprise application deployment is strategic for organizations today' [16]. Mobility is the principle that will influence all information systems developed in the future - as sooner or later the users will express their desire to access them from their tablet PCs or mobile phones.

\section{CONCLUSIONS}

1) An up-to-date electronic document management system has to be accessible from mobile devices.

2) Mobility of information systems is a crucially important factor in the public sector as managers are often not present in their workplace and require a remote access to documents and other resources of the organization.

3) For the time being the vast majority of DMS functions available from mobile devices are designed for users managers. It is foreseeable that in the near future with the development of technologies the range of functions will be expanded and mobile phones and tablet PCs will be used in order to create documents, insert the respective metadata and even perform capturing.

4) The growing number of mobile users is a new challenge for document management system developers - an opportunity to develop their products and make profit.

5) Developing and using a document management system involves careful consideration of security questions. Even if the organization chooses not to store sensitive data in the system, DMS can become a security breach. It is advisable that the system implementation project would employ a certified IT security specialist.

6) One has to consider that many workers use their own mobile devices to access the resources and information of the organization. This is a serious security risk.

7) The biggest DMS developers in the world also offer solutions for the most frequently used mobile platforms. However, when implementing a unique document management system accustomed to the needs of 
particular organization and this is being done, for instance, by a local IT company, it is compulsory to underline mobile access as one the requirements already in the purchase phase. Even if using the DMS from mobile devices is not necessary now, it may become a compulsory need during the near future.

8) In the future many document management systems will be developed for using them in the internet and a great part of them will be cloud-computing based.

\section{REFERENCES}

[1] S. Makinen, "Document management, organizational memory, and mobile environment," in Encyclopedia of Communities of Practice in Information and Knowledge Management, E. Coakes, S. Clarke, Eds. Idea Group Reference, United Kingdom: London, 2006, pp. 141-147.

[2] A. Gaffin, "Saros to give mobile Road Warriors document access," Network World, vol. 12, no. 14, pp. 8, April 31995.

[3] J. Senna, "DocsOpen moves to enterprise," Infoworld, vol. 18, no. 31 , pp. 95, July 291996.

[4] S. D. Nelson, J. W. Simek, and M. C. Maschke, The 2010 Solo and Small Firm Legal Technology Guide. Critical Decisions Made Simple, American Bar Association, United States of America: Chicago, 2010, ch. 16 .

[5] L. J. Sheela, R. Hemamalini, and M. Rejendran, "Cell phones the primary personal mobile computing devices," International Journal of Computer Trends and Technology, pp. 87-90, May-June issue, 2011.

[6] S. Makinen. (2005). Mobile Future - Issues and Records Management Responses. [Online]. Available: http://citeseerx.ist.psu.edu/viewdoc/summary?doi=10.1.1.165.3058

[7] D. Tang. (1st April 2012). The Rise of Mobile Data Capture and the Cloud in Document Management. [Online]. Available: http://www.imagesourcemag.com/ism-article/the-rise-mobile-data-cap ture-and-cloud-document-management

[8] S. Ristov, M. Gusev, and M. Kostoska, "Cloud computing security in business information systems," International Journal of Network Security \& Its Applications (IJNSA), vol. 4, no. 2, pp. 75-93, March 2012.

[9] K. W. Nafi, T. S. Kar, S. A. Hoque, and M. M. A. Hashem, "A newer user authentication, file encryption and distributed server based cloud computing security architecture," (IJACSA) International Journal of
Advanced Computer Science and Applications, vol. 3, no. 10, pp. 181-186, 2012

[10] S. Binu and J. Meenakumari, "A security framework for an enterprise system on cloud," Indian Journal of Computer Science and Engineering (IJCSE), vol. 3, no. 4, pp. 548-552, Aug-Sep 2012.

[11] V. R. Pandya and M. Stamp, "iphone security analysis," Journal of Information Security, vol. 1, pp. 74-87, 2010.

[12] K. Sharma, "Android in opposition to iPhone," International Journal on Computer Science and Engineering (IJCSE), vol. 3, no. 5, pp. 1965-1969, May 2011

[13] S. Zurier. (November 16th 2012). Multiple Paths to Document Management. [Online]. Available: http://www.fedtechmagazine.com/article/2012/11/multiple-paths-docu ment-management

[14] T. Leikums and R. Cevere, "Electronic document management Outsourcing and cloud-computing possibilities for public sector," in Proc. the 5-th International Scientific Conference Applied Information and Communication Technologies, ed. E. Stalidzans, pp. 55-61, 2012.

[15] A. W. Klein. (18th March 2012). Mobility Improves the Options for Document Management. [Online]. Available: http://voices.yahoo.com/mobility-improves-options-document-manag ement-11093222.html?cat=15

[16] S. N. Bal, "Mobile web - enterprise application advantages," International Journal of Computer Science and Mobile Computing, vol. 2, no. 2, pp. 36-40, February 2013.

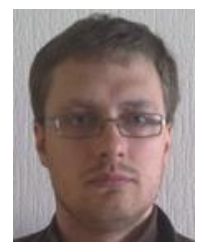

T. Leikums was born in Liepāja, Latvia, in 1984. He received the professional Bachelor degree in Programming from Latvia University of Agriculture (Jelgava, Latvia) in 2006, and professional Master degree in International Project Management from Latvia University of Agriculture in 2008. Currently he is a 3rd year $\mathrm{PhD}$ student in Latvia University of Agriculture, researching electronic document management. $\mathrm{T}$. Leikums is working at the Ministry for Agriculture of the Republic of Latvia and is responsible for electronic document circulation at the ministry and six of its largest affiliations. Working in the field of electronic document management, he has published many different studies. Mr. Leikums is a member of IACSIT 